${ }^{1}$ University of São Paulo, Faculty of Dentistry, Department of Social Dentistry, São Paulo, São Paulo, Brasil.

${ }^{2}$ Federal University of Juiz de Fora, Campus Governador Valadares, Department of Nutrition, Governador Valadares, Minas Gerais, Brasil

${ }^{3}$ Federal University of Juiz de Fora, Campus Governador Valadares, Department of Dentistry, Oral Diagnosis, Governador Valadares, Minas Gerais, Brasil

Corresponding author: Rebeca Cardoso Pedra, Federal University of Juiz de Fora, Department of Dentistry, Campus Governador Valadares. Raimundo Monteiro Rezende Avenue, 330, Governador Valadares - MG, 35010173, Brazil.

E-mail: rebecapedra@yahoo.com.br. Telefone: +5533011000

Editor: Dr Altair A. Del Bel Cury

Received: May 16, 2020

Accepted: February 2, 2021

\section{Factors associated with advanced-stage oral and oropharyngeal squamous cell carcinoma in a Brazilian population}

\author{
Rebeca Cardoso Pedra1,* (D), Clarice Lima Álvares da \\ Silva ${ }^{2}$ (D) Ismênia Edwirges Bernardes ${ }^{3}$ (D), Francielle \\ Silvestre Verner $^{3}$ (D), Karla Machado Andrade ${ }^{3}$ (D), \\ Rafael de Sousa Santos ${ }^{3}$ (D), Sibele Nascimento \\ de Aquino ${ }^{3}$ (i)
}

Diagnosis of oral and oropharyngeal cancer in advanced stages may be associated with social nature factors, access to health care, education, occupation, and behavioral/ cultural factors. Aim: To determine the factors related to high clinical-staging in patients diagnosed with squamous cell carcinoma in the oral and oropharyngeal region in a Cancer Center in Brazil between 2009 and 2015. Methods: It is an epidemiological, retrospective, and exploratory study. Patients diagnosed with squamous cell carcinoma had their medical records analyzed. The variables considered were sociodemographic, lifestyle, and disease characteristics. Descriptive and exploratory tests (Pearson's, chi-square test and, Student's t-test) were realized. Results: We analyzed 365 patient records, among which 289 (79.17\%) were male, and 73 (20.0\%) were female. Age ranged from 16 to 101 years, with a mean of 61.13. Regarding education, 157 (43.01\%) studied < 8 years, 103 (28.21\%) were illiterate and $102(27.94 \%)$ studied $>8$ years. $305(83.56 \%)$ patients live in urban areas. There was an association between high clinical-staging and low educational level. For high clinical-staging, symptomatology, tobacco, and alcohol intake as well. Conclusion: Patients with low educational levels tend to report the disease later, and their diagnostics occurred in advanced stages. Thus, specific public health policies for this population, including access to dental care to recognize the clinical signs and early diagnosis, are necessary.

KEYWORDS: Education status. Mouth neoplasms. Oropharyngeal neoplasms. Socioeconomic factors. 


\section{Introduction}

About 40 to $60 \%$ of patients diagnosed with oral and oropharyngeal squamous cell carcinoma (OPSCC) start the treatment in the advanced-stages of the disease $^{1}$. Several factors of social nature, such as the time between the disease perception, diagnosis, and treatment, are responsible for the disease identification in advanced-stages. Also, access to health care services, education, occupation, behavioral/cultural factors, exposure to risk factors such as tobacco, topographical distribution of the disease, and the tumor stage may affect the disease perception as well ${ }^{2}$.

Individuals in an underprivileged socioeconomic situation usually present a higher prevalence of head and neck cancer and inadequate medical access. Some authors identify socioeconomic status as the fundamental cause of inequalities in mortality and, therefore, relevant to health protection ${ }^{3,4}$. Socio-demographic characteristics are related to the advanced clinical staging of oral cancer and its diagnosis delay ${ }^{5}$. The delay in diagnosis compromises the treatment, its prognosis, and survival ${ }^{6}$.

Lack of health insurance affects access to the clinical examination of the oral and oropharyngeal region. It is a highly effective prevention strategy to detect cancerous lesions in their early stages, allowing a better prognosis and effective therapeutic intervention ${ }^{5}$ It is relevant to delineate the profile of individuals affected by OPSCC and identify the main risk factors associated with the disease's appearance, evolution, and survival to develop and implement primary and secondary public health measures. Also, dentists and physicians could be more accurate in oral examinations and population screening by being aware of this information. It may result in the improvement of public health measures for the prevention and control of OPSCC 1,6 Knowing the profile of these patients and identifying the factors associated with the late diagnosis will be useful for public policy formulation for the prevention and early diagnosis of OPSCC.

Thus, this study aims to describe the clinical and socio-demographic profile of patients who received treatment for OPSCC to evaluate the association between the socio-demographic and the disease characteristics with the clinical-staging at the diagnosis moment as well as to analyze possible associations between the tumoral subsite, socio-demographic characteristics, and disease evolution.

\section{MATERIALS AND METHODS}

It is a retrospective and exploratory study about the epidemiological profile of OPSCC cases treated in a cancer center in Governador Valadares, Minas Gerais state, between 2009 and 2015. Four hundred and five patients' medical records who had been diagnosed with head and neck cancer were analyzed. The inclusion criteria for medical records selection were to have an anatomopathological report description confirming the diagnosis during the period proposed in this study. The exclusion criteria were medical records without information or incomplete, for not allowing a proper data analysis. 
The dependent variables of this study were disease characteristics, including the histological type, tumor location, clinical-staging (subdivided in 1, 2, 3, 4 according to the degree of severity), treatment (chemotherapy, radiotherapy, surgery), clinical follow-up, and closure. The variables considered as independent for analyses were the socio-demographics: sex (male and female), age (years), marital status (single, married, divorced, widowed), educational level (<8 years of study, $\geq 8$ years, illiterate), occupation/employment classified according to Brazilian occupational code, residence location (urban or countryside), family history of cancer, tobacco (smoker and never smoker) and alcohol consumption (alcoholic and never drank).

Data collection in the medical records was monitored and verified by the coordinators of this research. Stata ${ }^{\circledR}$ version 13.0 (Stata Corp., College Station, United States) was the software applied for data tabulation and statistical analysis, with double data entry to control potential tabulation errors. The statistic tests selected were descriptive statistics (prevalence, absolute and relative frequency, means, and standard deviation) and exploratory tests (Pearson's chi-square test and Student's t-test), which adopted statistical significance of $5 \%(p<0.05)$.

The study was approved by the Ethics in Research with Human Beings Committee of the Federal University of Juiz de Fora (\#1.300.203) and with the 1964 Helsinki declaration and its later amendments.

\section{RESULTS}

Among the four hundred and five head and neck cases of cancer analyzed, we selected three hundred and sixty-five medical records of patients diagnosed with OPSCC. Age at diagnosis ranged between sixteen and one hundred and one years, and the mean age was 61,13 years. The majority of the patients were male. They studied for less than eight years, were married, and lived in the urban area (Table 1). Regarding occupation, one hundred and nine (30.28\%) patients were multipurpose agricultural workers and similar, followed by workers that cannot be classified by profession 65 (18.6\%), masons and plasterers 25 (6.94\%), and specialized agricultural workers not classified under other headings 22 (6.11\%), among other less frequent occupations as well.

Regarding habits, $84.65 \%$ were smokers, and $67.4 \%$ used to consume alcohol regularly. The health care used for $92.31 \%$ of the patients was the Brazilian public health system, Sistema Único de Saúde or Health Unic System (SUS), and 24 (6.59\%) used private health care. Disease identification occurred predominantly by medical professionals (84.65\%) (Table1).

The most affected anatomic sites were oropharynx 151 (48.55\%), tongue 114 (36.65\%), palate 34 (10.93\%), and floor of the mouth 12 (3.85\%). As diagnostic methods, we identified clinical examination and biopsy used in 223 (61.10\%) cases and the combination of clinical examination, biopsy, and imaging exam in 124 (33.97\%) patients. 
Table 1. Sociodemographic and clinical characteristics of patients with squamous cell carcinoma.

\begin{tabular}{|c|c|c|c|}
\hline Sociodemographic data & & $\mathrm{n}$ & $\%$ \\
\hline \multirow{3}{*}{ Gender } & Male & 289 & $79.17 \%$ \\
\hline & Female & 73 & $20.0 \%$ \\
\hline & No information & 03 & $0.82 \%$ \\
\hline \multirow{4}{*}{ Education } & No & 103 & $28.21 \%$ \\
\hline & $<8$ years & 157 & $43.01 \%$ \\
\hline & >8years & 102 & $27.94 \%$ \\
\hline & No information & 03 & $0.82 \%$ \\
\hline \multirow{5}{*}{ Marital Status } & Single & 78 & $21.49 \%$ \\
\hline & Married & 201 & $55.06 \%$ \\
\hline & Divorced & 30 & $8.21 \%$ \\
\hline & Widowed & 54 & $17.79 \%$ \\
\hline & No information & 02 & $0.54 \%$ \\
\hline \multirow{3}{*}{ Residence } & Urban & 305 & $83.56 \%$ \\
\hline & Countryside & 58 & $15.89 \%$ \\
\hline & No information & 02 & $0.54 \%$ \\
\hline \multirow{2}{*}{ Smoke } & No & 56 & $15.34 \%$ \\
\hline & Yes & 309 & $84.65 \%$ \\
\hline \multirow{2}{*}{ Alcohol } & No & 119 & $32.60 \%$ \\
\hline & Yes & 246 & $67.4 \%$ \\
\hline \multirow{4}{*}{ Referral Professional } & Dentist & 32 & $8.76 \%$ \\
\hline & Physician & 309 & $84.65 \%$ \\
\hline & Other & 6 & $1.64 \%$ \\
\hline & No information & 18 & $4.93 \%$ \\
\hline \multirow{2}{*}{ Family history of cancer } & No & 273 & $74.79 \%$ \\
\hline & Yes & 92 & $25.21 \%$ \\
\hline
\end{tabular}

The majority of patients reported symptoms (80.38\%). The most common were pain reported by $75.50 \%$ of patients, feed struggles by $74.17 \%$, speech difficulties by $24.17 \%$, trismus by $18.54 \%$, and $32.78 \%$ felt other symptoms. When comparing the symptomatology reports between the same cancer subsites, some locations were more symptomatic: in the tongue (96 of 114), mouth floor (09 of 12), ridge (04 of 05), buccal mucosa (05 of 07 ), oropharynx (121 of 151), retromolar area (07 of 07), and soft palate (27 of 33). There was no report of symptoms in the lips.

The most common clinical-staging (CS) among patients at the beginning of the treatment was CS 4 , with $55.68 \%$ of patients, followed by CS 3 with $26.99 \%$. Cervical lymphadenopathy was present in $60.44 \%$ of the patients. Among them, $68.66 \%$ had unilateral lymphadenopathy, and $31.34 \%$ had it bilaterally. Forty (11.02\%) patients had metastasis. Twenty of them were in the lungs, six in the brain, and 5 in the liver and bones. The treatments available were surgery, chemotherapy, and radiotherapy. A large number of patients received treatment but remained with the disease in progress. Death was a frequent outcome (Table 2). 
Analyzing clinical-staging in OPSCC according to sociodemographic and clinical characteristics, we found association between worse CS and educational level, symptoms, smoking habit, and alcohol consumption. However, we did not find a significant association with gender (Table 3).

There was no significant association between alcohol and tobacco consumption or education level and death.

Table 2. Patient treatment data and outcomes of patients with squamous cell carcinoma.

\begin{tabular}{|c|c|c|c|}
\hline Treatment & & n (363) & $\%$ \\
\hline No & & 74 & $20.39 \%$ \\
\hline Yes & & 289 & $79.61 \%$ \\
\hline Treatment received & & n (289) & $\%$ \\
\hline \multirow{2}{*}{ Surgery } & No & 263 & $91.00 \%$ \\
\hline & Yes & 26 & $9.00 \%$ \\
\hline \multirow{2}{*}{ Chemotherapy } & No & 72 & $24.91 \%$ \\
\hline & Yes & 217 & $75.09 \%$ \\
\hline \multirow{2}{*}{ Radiotherapy } & No & 71 & $24.57 \%$ \\
\hline & Yes & 218 & $75.43 \%$ \\
\hline \multirow{7}{*}{ Disease follow up } & Disease progressing & 153 & $42.15 \%$ \\
\hline & Complete remission & 80 & $22,04 \%$ \\
\hline & No information & 50 & $13.77 \%$ \\
\hline & Stable disease & 30 & $8.26 \%$ \\
\hline & No therapeutic possibility & 18 & $4.96 \%$ \\
\hline & Partial remission & 17 & $4.68 \%$ \\
\hline & Abandoned the treatment & 15 & $4.13 \%$ \\
\hline \multirow{2}{*}{ Death } & No & 175 & $48.21 \%$ \\
\hline & Yes & 188 & $51.79 \%$ \\
\hline
\end{tabular}

Table 3. Analysis of clinical-staging in oral and oropharyngeal squamous cell carcinoma according to sociodemographic and clinical characteristics.

\begin{tabular}{|c|c|c|c|c|c|c|}
\hline \multicolumn{2}{|c|}{ Patients per stage } & 18 & 41 & 95 & 195 & \multirow{2}{*}{$\mathrm{p}$-value } \\
\hline Clinical-Stac & & 1 & 2 & 3 & 4 & \\
\hline \multirow{2}{*}{ Alcoholism } & No & $11(61.11 \%)$ & $19(44.19 \%)$ & $34(35.79 \%)$ & $49(25.00 \%)$ & \multirow{2}{*}{0.002} \\
\hline & Yes & $7(38.89 \%)$ & $24(55.81 \%)$ & $61(64.21 \%)$ & $147(75.00 \%)$ & \\
\hline \multirow{2}{*}{ Smoking } & No & $8(44.44 \%)$ & $8(18.60 \%)$ & $12(12.63 \%)$ & $23(11.73 \%)$ & \multirow{2}{*}{0.002} \\
\hline & Yes & $10(55.56 \%)$ & $35(81.40 \%)$ & $83(87.37 \%)$ & $173(88.27 \%)$ & \\
\hline \multirow{2}{*}{ Symptoms } & No & $11(64.71 \%)$ & $8(19.51 \%)$ & $16(16.84 \%)$ & 21 (10.77\%) & \multirow{2}{*}{0.000} \\
\hline & Yes & $6(35.29 \%)$ & $33(80.49 \%)$ & 79 (83.16\%) & 174 (89.23\%) & \\
\hline \multirow{3}{*}{$\begin{array}{l}\text { Educational } \\
\text { level }\end{array}$} & $>8$ years & $11(61.11 \%)$ & $16(38.10 \%)$ & $27(28.72 \%)$ & $43(22.05 \%)$ & \multirow{3}{*}{0.015} \\
\hline & $<8$ years & $5(27.78 \%)$ & $15(35.71 \%)$ & $39(41.49 \%)$ & $92(47.18 \%)$ & \\
\hline & No & $2(11.11 \%)$ & $11(26.19 \%)$ & $28(29.79 \%)$ & $60(30.77 \%)$ & \\
\hline \multirow{2}{*}{ Gender } & Female & $6(33.33 \%)$ & $10(24.39 \%)$ & $23(24.21 \%)$ & $32(16.41 \%)$ & \multirow{2}{*}{0.170} \\
\hline & Male & $12(66.67 \%)$ & $31(75.61 \%)$ & 72 (75.79\%) & 163 (83.59\%) & \\
\hline
\end{tabular}




\section{DISCUSSION}

This study describes the clinical and sociodemographic aspects of 365 cases of OPSCC, and the results show that educational level, consumption of tobacco, and alcohol are associated with high CS.

The patients in our study were predominantly low educated men who lived in urban areas. They were rural workers, and their OPSCC diagnosis occurred in advanced CS. Patients with oral and oropharyngeal cancer might face many social nature factors that could affect their health condition. Most of them have a low educational level and low financial income, which usually are associated with a high risk for cancer due to late diagnosis and high morbidity rates ${ }^{7,8}$. Our findings are characteristic from developing countries where the diagnosis commonly occurs at advanced CS. Otherwise, in developed countries, the CS most common at diagnosis are I and II. Probably due to the highest educational levels and better health care access ${ }^{7,9}$.

Low educational level and socioeconomic status are also considered risk factors to develop and die from other types of cancer. In lung cancer, the prevalence and intensity of smoking were associated with educational level and mortality among men ${ }^{10,11}$. The highest educational inequalities are associated with mortality from lung, esophagus head and neck cancer in European studies ${ }^{12,13}$. Compared to highly educated men, low educated men were about 2.2 (95\% Cl: $2.1-2.3)$ and 2.0 (95\% Cl: 1.7-2.2) times more likely to die from lung and head and neck cancer, respectively ${ }^{12}$.

The association between education level, risk factors, and advanced CS observed in our study is similar to the results observed in the literature?. Low-educated men are more inclined to smoke, which is a high associated risk factor with the development of OPSCC, especially if combined with alcohol consumption 9,12,14,15. The educational level influence the presence of the risk factors in these patients' lives. The ideal solution to prevent the disease from reaching this stage is early diagnosis. Although the public absence of knowledge about the OPSCC compared to other cancers is a challenge to the auto-perception of disease signs and symptoms. The lack of dental examinations and the patient's fear of them also contribute to the diagnostic delay ${ }^{16}$.

Diagnosis in advanced CS brings a treatment challenge insofar as, in these stages, the prognosis worsens. In our findings, there was a positive association between a symptomatology increase and advanced CS, few patients have achieved complete remission in the disease follow up, and more than $50 \%$ died. Patients classified in high stages present patterns of bigger and invasive lesions ${ }^{17}$. These tumor standards, when associated with the anatomical characteristics of the subsites mainly affected, explains the high symptomatology presence and its CS associations. Also, the low number of patients submitted to surgeries, which might result in poor functional outcome ${ }^{18}$.

A study with 646 patients found that localized swelling, pain, and alterations of the mucosa were the predominant signs and symptoms of the disease in advanced CS in most cases. The hospitalization rate was high, corresponding to $66.9 \%$ of patients after four months of the first symptoms notification. In our study, we found similar findings regarding symptomatology (75.50\% pain) and clinical staging. Patients clas- 
sified in high stages presented patterns of bigger and invasive lesions ${ }^{17}$, which are related to symptomatology.

Physicians were responsible for most patient's referral and the diagnosis. The low participation of dentists in the diagnosis is a critical finding. Dentists should be responsible for the primary prevention of oral cancer by identifying precancerous lesions, advising on smoking cessation, alcohol diminution, and sun protection ${ }^{19}$. OPSCC were diagnosed in the early stages by dentists than to physicians ${ }^{20,21}$. Regular dental visits were also associated with diagnosis at early stages ${ }^{21}$. Dentists are essential in the early diagnosis of oral cancer since they have access to all oral and oropharyngeal regions during clinical examinations ${ }^{22}$.

The preponderant part of the patients in our study worked in the countryside. Rural areas usually are characterized by higher rates of poverty and tobacco use. Generally, they have worse education levels, lower incomes, and socioeconomic status. Rural residents may also indirectly have limited access to care, such as low availability of specialty health facilities and long travel times. Consequently, patients from these areas have higher incidence and mortality rates for tobacco-related cancer 23,24 Besides that, in Brazil, rural populations have poor access to oral public health services in comparison to those from urban areas ${ }^{25}$.

Tobacco and alcohol consumption are the etiological factors most associated with the development of oral squamous cell carcinoma ${ }^{9,14,15}$. Similarly to our findings, a study has associated alcohol and tobacco consumption with advanced clinical staging ${ }^{7}$. These risk factors contribute to the disease worsening, and the diagnosis delay results in high morbidity rates ${ }^{1}$. In our study, most patients died because of OPSCC, during or after treatment. These are facts that urge attention to the need to implement more effective public policies that strongly encourage early diagnosis enabling these patients to have more effective treatment, better prognosis, and survival rates ${ }^{6}$.

In our study, we observed that educational level deepens cultural limits. It brings harmful habits to population health, to those who have less access to education. The low education level might influence consumption patterns affecting health negatively with risky habits. Public policies that encourage schooling are also relevant for preventing OPSCC not only to provide economic growth ${ }^{12}$. Social inequality goes even further, transcending cultural issues. The at-risk population, being rural, face difficulties accessing health services. Health policies in SUS that guide active searches on the communities who live or work in rural areas and are smokers are needed to promote health education and OPSCC early detection. Besides, encourage greater participation by dental surgeons in these actions, especially in rural areas ${ }^{13}$.

OPSCC is a health problem that, to be combated effectively, poses a massive challenge for public policy elaboration. It demands that the policies developed should involve the citizen needs globally. For effective prevention, it is crucial to improve educational levels and access to health care. Besides, it is also necessary to approach the rural population and health services. Promote a better involvement of dental professionals in this issue as well. These actions could culminate in the achievement of better results as an early disease diagnosis ${ }^{25,26}$. 
The present study demonstrates that low educational level, smoking, and symptoms may be related to the diagnosis of oral and oropharyngeal cancer at advanced clinical-staging. Therefore, it is relevant to implement specific public policies to improve this population's health. including the information about this disease to the inhabitants with low educational levels and improve their access to dental care in order to recognize the clinical signs and early diagnosis.

\section{REFERENCES}

1. Gigliotti J, Madathil S, Makhoul N. Delays in oral cavity cancer. Int J Oral Maxillofac Surg. 2019; 48(9):1131-7. doi: 10.1016/j.ijom.2019.02.015.

2. Dantas TS, de Barros Silva PG, Sousa EF, da Cunha MDP, de Aguiar AS, Costa FW, et al. Influence of educational level, stage, and histological type on survival of oral cancer in a brazilian population. Medicine (Baltimore). 2016; 95(3):e2314. doi: 10.1097/md.0000000000002314.

3. Phelan J, Link B, Diez-Roux A, Kawachi I, Levin B. "Fundamental Causes" of Social Inequalities in Mortality: A Test of the Theory. J Health Soc Behav. 2004; 45(3):265-85. doi: 10.1177/002214650404500303.

4. Syse A, Lyngstad T. In sickness and in health: The role of marital partners in cancer survival. SSM Popul Health. 2017; 3:99-110. doi: 10.1016/j.ssmph.2016.12.007.

5. Lins LS, Bezerra NV, Freire AR, Almeida LD, Lucena EH, Cavalcanti YW. Socio-demographic characteristics are related to the advanced clinical stage of oral cancer. Med Oral Patol Oral Cir Bucal. 2019; 24(6):e759-63. doi: 10.4317/medoral.23105.

6. Moro JS, Maroneze MC, Ardenghi TM, Barin LM, Danesi CC. Oral and oropharyngeal cancer: epidemiology and survival analysis. Einstein (Sao Paulo). 2018;16(2):1-5. doi: 10.1590/s1679-45082018ao4248.

7. Santos HB, dos Santos TK, Paz AR, Cavalcanti YW, Nonaka CFW, Godoy GP, et al. Clinical findings and risk factors to oral squamous cell carcinoma in young patients: a 12-year retrospective analysis. Med Oral Patol Oral y Cir Bucal. 2016;21(2):e151-6. doi: 10.4317/medoral.20770.

8. American Cancer Society. Cancer Facts \& Figures. Atlanta: American Cancer Society; 2018.

9. Alves AM, Correa MB, Silva KD, Araújo LMA, Vasconcelos ACU, Gomes APN, et al. Demographic and clinical profile of oral squamous cell carcinoma from a Service-Based Population. Braz Dent J. 2017; 28(3):301-6. doi: 10.1590/0103-6440201601257.

10. Mathew A, George PS, Kunnambath R, Mathew BS, Kumar A, Syampramod R, et al. Educational Status, Cancer Stage, and Survival in South India: A Population-Based Study. JCO Glob Oncol. 2020;6:1704-11. doi: 10.1200/G0.20.00259.

11. Osazuwa-Peters N, Adjei Boakye E, Hussaini AS, Sujijantarat N, Ganesh RN, Snider M, et al. Characteristics and predictors of oral cancer knowledge in a predominantly African American community. PLoS One. 2017;17;12(5):e0177787. doi: 10.1371/journal.pone.0177787.

12. Vanthomme K, Vandenheede H, Hagedoorn P, Gadeyne S. Evolution of educational inequalities in site-specific cancer mortality among Belgian men between the 1990s and 2000s using a "fundamental cause" perspective. BMC Cancer. 2017;17(1):470. doi: 10.1186/s12885-017-3461-8.

13. Mackenbach JP, Kulhánová I, Bopp M, Deboosere P, Eikemo TA, Hoffmann R, et al. Variations in the relation between education and cause-specific mortality in 19 European populations: A test of the "fundamental causes" theory of social inequalities in health. Soc Sci Med. 2015;127:51-62. doi: 10.1016/j.socscimed.2014.05.021. 
14. Alam M, Siddiqui S, Perween R. Epidemiological profile of head and neck cancer patients in Western Uttar Pradesh and analysis of distributions of risk factors in relation to site of tumor. $J$ Cancer Res Ther. 2017;13(3):430-5. doi: 10.4103/0973-1482.180687.

15. Peltanova B, Raudenska M, Masarik M. Effect of tumor microenvironment on pathogenesis of the head and neck squamous cell carcinoma: a systematic review. Mol Cancer. 2019;18(1):63. doi: 10.1186/s12943-019-0983-5.

16. Logan HL, Guo Y, Marks J. Disparities in survival patterns for oral and pharyngeal cancer in Florida: can we do anything about it? Today's FDA. 2015;27(4):58-61.

17. Crescenzi D, Laus M, Radici M, Croce A. TNM classification of the oral cavity carcinomas: some suggested modifications. Otolaryngol Pol. 2015;69(4):21-30. doi: 10.5604/00306657.1160919.

18. Alzahrani R, Obaid A, Al-Hakami H, Alshehri A, Al-Assaf H, Adas R, et al. Locally Advanced Oral Cavity Cancers: What Is The Optimal Care?. Cancer Control. 2020;27(1):1073274820920727. doi: 10.1177/1073274820920727.

19. Gigliotti J, Madathil S, Makhoul N. Delays in oral cavity cancer. Int J Oral Maxillofac Surg. 2019;48(9):1131-7. doi: 10.1016/j.ijom.2019.02.015.

20. Langton S, Cousin GCS, Plüddemann A, Bankhead CR. Comparison of primary care doctors and dentists in the referral of oral cancer: a systematic review. Br J Oral Maxillofac Surg. 2020;58(8):898-917. doi: 10.1016/j.bjoms.2020.06.009.

21. Ghantous Y, Yaffi V, Abu-Elnaaj I. [Oral cavity cancer: epidemiology and early diagnosis]. Refuat Hapeh Vehashinayim (1993). 2015;32(3):55-63, 71. Hebrew.

22. Abadeh A, Ali A, Bradley G, Magalhaes M. Increase in detection of oral cancer and precursor lesions by dentists. J Am Dent Assoc. 2019;150(6):531-9. doi: 10.1016/j.adaj.2019.01.026.

23. Zuniga S, Lango M. Effect of rural and urban geography on larynx cancer incidence and survival Laryngoscope, 2018;128(8):1874-80. doi: 10.1002/lary.27042.

24. Roberts ME, Doogan NJ, Kurti AN, Redner R, Gaalema DE, Stanton CA, et al. Rural tobacco use across the united states: how rural and urban areas differ, broken down by census regions and divisions. Health Place. 2016;39:153-9. doi: 10.1016/j.healthplace.2016.04.001.

25. Arruda NM, Maia AG, Alves LC. Inequality in access to health services between urban and rural areas in Brazil: a disaggregation of factors from 1998 to 2008. Cad Saude Publica. 2018;34(6):e00213816. doi: 10.1590/0102-311x00213816.

26. Cunha A, Prass T, Hugo F. Mortality from oral and oropharyngeal cancer in Brazil: impact of the National Oral Health Policy. Cad Saude Publica. 2019;35(12):e00014319. doi: 10.1590/0102-311x00014319. 